\title{
First confirmed occurrence of the yellow fever virus and dengue virus vector Aedes (Stegomyia) luteocephalus (Newstead, 1907) in Mozambique
}

Ana Paula Abílio ${ }^{1,2^{*}} \mathbb{0}$, Ayubo Kampango ${ }^{1}$, Eliseu J. Armando ${ }^{3}$, Eduardo S. Gudo ${ }^{1}$, Luís C. B. das Neves ${ }^{2,4}$, Ricardo Parreira ${ }^{5}$, Mohsin Sidat ${ }^{2,5}$, José M. Fafetine ${ }^{2,4}$ and António Paulo G. de Almeida ${ }^{5}$

\begin{abstract}
Background: Mozambique, same as many other tropical countries, is at high risk of arthropod-borne virus (arbovirus) diseases and recently two dengue virus (DENV) outbreaks occurred in the northern part of the country. The occurrence of some important vector species, such as Aedes (Stegomyia) aegypti (Linnaeus) and Ae. (Stg.) albopictus (Skuse), besides several other sylvatic vectors, have been reported in the country, which may indicate that the transmission of some arboviruses of public health importance may involve multiple-vector systems. Therefore, knowing the occurrence and distribution of existing and the new important vectors species, is crucial for devising systematic transmission surveillance and vector control approaches. The aim of this study was to map the occurrence and distribution of mosquito species with potential for transmitting arboviruses of human and veterinary relevance in Niassa Province, Northern Mozambique.

Methods: Field entomological surveys were undertaken in April 2016 in Lago District, Niassa Province, northern Mozambique. Breeding sites of mosquitoes were inspected and immature stages were collected and reared into adult. Mosquitoes in the adult stages were morphologically identified using taxonomic keys. Morphological identification of Aedes (Stegomyia) luteocephalus (Newstead) were later confirmed using dissected male genitalia and molecular based on the phylogenetic analyses of the sequenced barcode (cox $1 \mathrm{mtDNA}$ ) gene.

Results: A total of 92 mosquito larvae collected developed into adults. Of these, 16 (17.39\%) were morphologically identified as Ae. luteocephalus. The remaining specimens belonged to Ae. (Stg.) aegypti ( $n=4,4.35 \%)$, Ae. (Aedimorphus) vittatus ( $n=24,26.09 \%)$, Anopheles garnhami $(n=1,1.09 \%)$, Culex (Culiciomyia) nebulosus $(n=28,30.43 \%)$, Eretmapodites subsimplicipes ( $n=18,19.57 \%$ ) and Toxorhynchites brevipalpis $(n=1,1.09 \%)$, taxa already known to the country. Male genitalia and phylogenetic analyses confirmed the identity of Ae. luteocephalus specimens collected in this study.

Conclusions: To our knowledge, this is the first detection of Ae. luteocephalus in Mozambican territory, a vector species of yellow fever virus (YFV), Zika virus (ZIKV) and dengue virus (DENV) in Africa. Further studies are encouraged to investigate the role of Ae. luteocephalus in the transmission of arboviral diseases in Mozambique.
\end{abstract}

Keywords: New record, Arthropod-borne, Virus, Vector, Aedine, Mosquito

*Correspondence: anabilio1408@gmail.com

${ }^{1}$ Instituto Nacional de Saúde (INS), Maputo, Província de Maputo, Mozambique

Full list of author information is available at the end of the article

c) The Author(s) 2020. This article is licensed under a Creative Commons Attribution 4.0 International License, which permits use, sharing, adaptation, distribution and reproduction in any medium or format, as long as you give appropriate credit to the original author(s) and the source, provide a link to the Creative Commons licence, and indicate if changes were made. The images or other third party material in this article are included in the article's Creative Commons licence, unless indicated otherwise in a credit line to the material. If material is not included in the article's Creative Commons licence and your intended use is not permitted by statutory regulation or exceeds the permitted use, you will need to obtain permission directly from the copyright holder. To view a copy of this licence, visit http://creativeco mmons.org/licenses/by/4.0/. The Creative Commons Public Domain Dedication waiver (http://creativecommons.org/publicdomain/ zero/1.0/) applies to the data made available in this article, unless otherwise stated in a credit line to the data. 


\section{Background}

The occurrence and distribution of mosquito-borne arboviruses, particularly those transmitted by Aedes species, such as dengue (DENV), Zika (ZIKV) and yellow fever viruses (YFV) represent a serious threat to global health, particularly to African sub-Saharan countries [1-6]. It has been estimated that annually nearly 3,312,040 cases and 4,032 deaths of DENV infections occur worldwide $[3,7]$. Zika virus, on the other hand, has been declared a public health emergency of international concern since 2016 [6]. Likewise, re-emergence of yellow fever cases has been lately observed in some African countries and Brazil, despite the existence of an effective vaccine that could protect populations and control the disease [8].

Mozambique is home to several mosquito species, some of which are widely known and suspected arbovirus vectors [6, 9-11]. However, the role of the country's mosquito fauna in sustaining the transmission of endemic arboviral diseases such as dengue, yellow fever and chikungunya still remains poorly understood. One possible reason for such neglect may be due to the overwhelming number of malaria transmission cases that has been recorded throughout the country [12]. Most recently, two dengue virus outbreaks were observed in the northern region of Mozambique amounting to thousands of cases of infection [13, 14]. Likewise, the presence of major arbovirus vectors such as Ae. (Stg.) aegypti and Ae. (Stg.) albopictus, besides others with a more sylvatic distribution, has been reported in the country [6, 9], implying that arbovirus transmission dynamics may likely involve multiple-vector systems. These findings underscore the need for a thorough understanding of occurrence and arbovirus transmission role, of overlooked important potential vectors of public health importance. Aedes (Stg.) luteocephalus (henceforth, Ae. luteocephalus) is a mosquito species native to Africa, reported in circa twenty countries, particularly in the western and central regions of the continent, as well as in southern African countries such as Botswana and Zimbabwe [15-22]. This species has varied distribution throughout different geographical landscapes comprising forests, savannah, mangrove gallery, as well as intermediate landscapes between sylvatic and urban areas, where it has been found breeding in a diversity of natural and human-made larval sites $[15,17$, 20].

Aedes luteocephalus is a competent vector for YFV [23] and can be an important vector of ZIKV and DENV, as observed in competence assays elsewhere in West and Central Africa [17, 20, 24]. Therefore, an in-depth understanding of the occurrence and distribution of these important vectors of arboviruses is crucial for devising accurate and effective evidence-based transmission control measures. The aim of this study was to map the occurrence and distribution of mosquito species with potential of transmitting arboviruses of human and veterinary relevance in the region.

Therefore, this report represents, to the best of our knowledge, the first confirmed record of Ae. luteocephalus in Mozambique. The implication of this discovery in the design of arthropod-borne virus (arbovirus) surveillance and control measures in Mozambique is briefly discussed.

\section{Methods}

\section{Study site and sampling strategy}

Entomological field surveys were conducted in April of 2016 in Lago District, neighborhood of Maniamba $\left(12^{\circ} 41.881^{\prime} \mathrm{S}, 34^{\circ} 48.539^{\prime} \mathrm{E}\right)$, Niassa Province in northern Mozambique. All potential types of natural and artificial mosquito breeding sites were surveyed for the presence of mosquito immature stages. Mosquito larvae and pupae were sampled following standard operating procedures [25]. Additionally, used car tyres filled with water were placed for approximately $500 \mathrm{~m}$ apart in a transect along the main road crossing Chapama forest and Luaui River in an effort to collect as many samples as possible at different sites in the vicinity, to better sample the area. The tyres were left in the field for 8 days, after which they were surveyed for immature mosquitoes. Each breeding place was surveyed using a Pasteur pipette. Collected specimens were sorted, placed in the $500 \mathrm{ml}$ plastic bottles, filled up to $75 \%$ of water from specific breeding place and labelled accordingly. All samples collected were then transported to local insectaries for rearing to adults $[25,26]$. Preliminary morphological identification was conducted on adult stages emerged, using taxonomic keys [15, 21, 27-29]. Adult specimens were preserved individually in single $1.5 \mathrm{ml}$ Eppendorf tubes at $-80{ }^{\circ} \mathrm{C}$ for further morphological and molecular analysis. Whole mosquitoes, male and female, of $A e$. luteocephalus were re-observed and male terminalia were separated from the abdomen and adsorbed in Marc André solution [27]. Genitalia were dissected under stereomicroscope and mounted in formic acid-polyvinyl alcohol (PVA) solution between a slide and a cover slip $[27,28]$ and photographed under Olympus stereomicroscope SZ51 (Olympus, Seoul, South Korea), Olympus microscope (BX51, Olympus, Seoul, South Korea) and an Olympus SC30 digital camera (Olympus, Tokyo, Japan), respectively. 


\section{Molecular analyses of adult mosquito specimens}

Genomic DNA was extracted from remaining the abdomen and legs of 4 males, as described in Mixão et al. [27]. Molecular analysis was targeted at the barcoding section between positions 58 to 705 encoding the $\mathrm{N}$-terminal section of the mitochondrial cytochrome $c$ oxidase subunit 1 gene (cox $1 \mathrm{mtDNA}$ ). Amplification of $\operatorname{cox} 1 \mathrm{mtDNA}$ was performed using LCO1490 and HCO2198 specific primers under PCR conditions as described by Folmer et al. [30]. The nucleotide (nt) sequences obtained were deposited in GenBank [31] under the accession numbers LC536733-LC536736).

The degree of correspondence between the barcode cox 1 mtDNA gene sequences obtained in this study were compared against those at GenBank database using BLASTn, (https://blast.ncbi.nlm.nih.gov/Blast.cgi) and Barcode of Life Data Sytems-v4 (http://www.boldsystems.org/) [32].

Phylogenetic reconstructions using cox 1 molecular data were carried out from multiple alignments of $n t$ sequences obtained using the iterative G-INS-I method as implemented in MAFFT v. 7 [33]. Subsequently, attained sequences were edited using both GBlocks [34] and visual inspection using BioEdit 7.0.5 [35] to ensure the correct alignment of homologous codons. Phylogenetic analysis was carried out using the Maximum Likelihood (ML) optimization criterion and GTR $+\Gamma+\mathrm{I}$ (GTR-General Time Reversal, $\Gamma$-Gamma distribution, I-proportion of invariant sites) as the dataset best-fitting evolutionary model, as suggested by jModelTest2 [36]. The ML phylogenetic tree was constructed with W-IQtree [37], using the bootstrap test (with 1000 random data resampling's) for assessment of the tree topological stability. The tree was edited with FigTree 1.4.4 (http:// tree.bio.ed.ac.uk/software/figtree/). Due to the lack of a satisfactory number of examined sequences and collected specimens, we were unable to run haplotype network analysis for robust inference of the origin of Ae. luteocephalus collected in this study.

\section{Results and discussion}

A total of 92 adult mosquitoes emerged from collected larvae and pupae; of these, 16 were tentatively identified as Ae. luteocephalus (12 females and 4 males) based on morphological features. The remaining specimens were identified as Anopheles (Celia) garnhami $(n=1), A e$. (Aedimorphus) vittatus $(n=24)$, Ae. (Stg.) aegypti $(n=4)$, Culex (culiciomyia) nebulosus $(n=28)$, Eretmapodites subsimplicipes $(n=18)$ and Toxorhynchites brevipalpis $(n=1)$ (Table 1).

Ten females of Ae. luteocephalus collected in this survey were deposited in the insect depository of Instituto Nacional de Saúde (INS) in Maputo Province, Mozambique, stored in individual Eppendorf ${ }^{\circledR}$ tubes (accession numbers MZ113-a1.2, a1.4-a1.12) and 6 specimens (2 females and 4 males) deposited in the Entomoteca (Insect collection) of the Institute of Hygiene and Tropical Medicine (IHMT), Lisbon, Portugal (accession numbers MZ113-a1.1-a1.3 and MZ113-a2.1-a2.4).

All 16 larvae, which gave rise to the adults Ae. luteocephalus and 5 Ae. vittatus were found cohabiting in a rock-pool of clear water, with approximately $20 \times 15 \mathrm{~cm}$ (Additional file 1: Figure S1), located at the Luaui riverbank and exposed to sunlight. Other species including the remaining 19 Ae. vittatus were obtained from other breeding sites, namely the tyres that were placed as "ovitraps", while no specimens of Ae. luteocephalus were obtained from any other breeding site (Table 1 ).

Table 1 Date of collection, mosquito species, sex, their respective niches, percentage (\%) and number of mosquitoes collected from Mozambique

\begin{tabular}{|c|c|c|c|c|}
\hline Date of collection & Habitat & Species & $\operatorname{Sex}(n)$ & Subtotal (\%) \\
\hline \multirow[t]{2}{*}{1 April 2016} & \multirow[t]{2}{*}{ Rock-pool of clear water } & Aedes (Stegomyia) luteocephalus & $M(4) / F(12)$ & $16(17.39)$ \\
\hline & & Aedes (Aedimorphus) vittatus & $M(5)$ & $5(5.43)$ \\
\hline \multirow[t]{6}{*}{8 April 2016} & \multirow[t]{6}{*}{ Tyre placed as "ovitraps" } & Anopheles (Celia) garnhani & $M(1)$ & $1(1.09)$ \\
\hline & & Aedes (Stegomyia) aegypti & M (4) & $4(4.35)$ \\
\hline & & Aedes (Aedimorphus) vittatus & $M(3) / F(16)$ & $19(20.65)$ \\
\hline & & Culex (Culiciomyia) nebulosus & $M(10) / F(18)$ & $28(30.43)$ \\
\hline & & Eretmapodites subcimplicipes & $M(3) / F(15)$ & $18(19.57)$ \\
\hline & & Toxorhynchites brevipalpis & $F(1)$ & $1(1.09)$ \\
\hline Total collected & & & & 92 \\
\hline
\end{tabular}



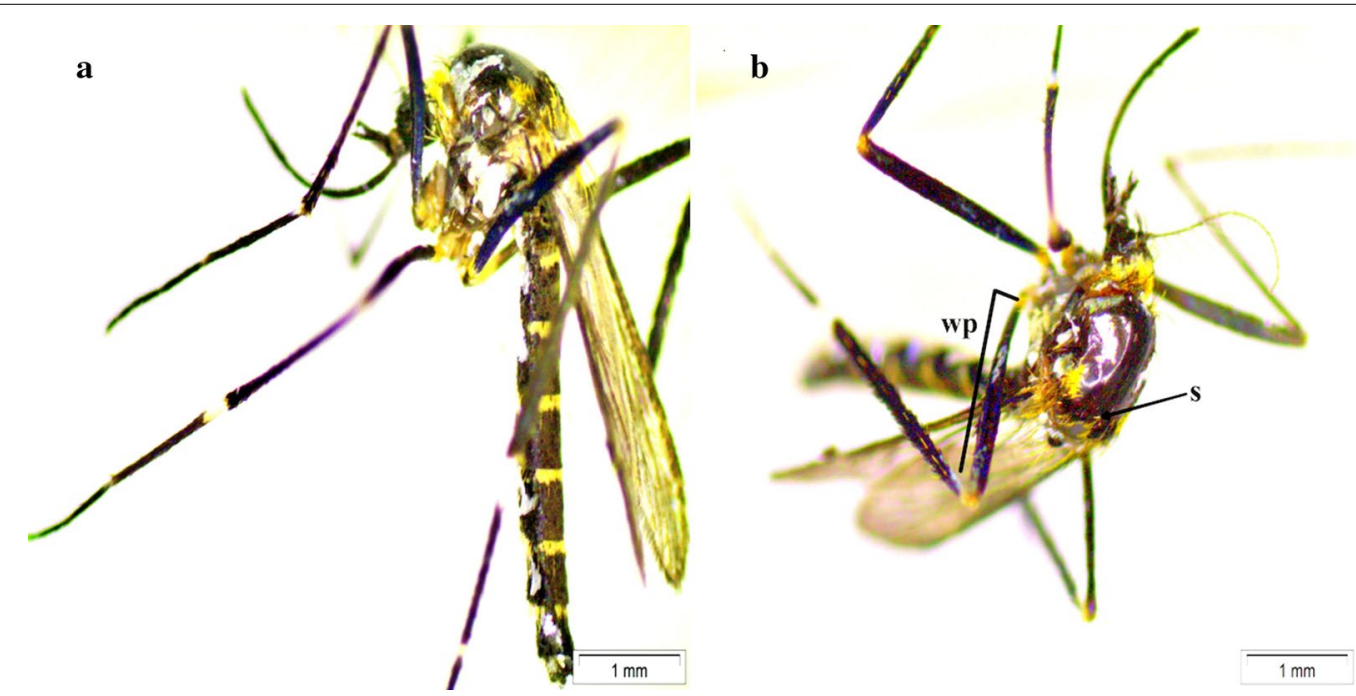

Fig. 1 a Adult female of Aedes luteocephalus specimen showing general characters. b Adult specimen highlighting the main diagnostic features including for the scutum (with median-longitudinal yellow stripe) (s) and hind tarsomere anteriorly with large pale band at base and two large white patches on median and apical areas (wp), both images at 20x magnification

Exhaustive studies are required to collect more information about Ae. luteocephalus distribution and infestation to better understand the importance of this and other arbovirus vectors throughout the country.

The habitat where they were found corresponds to its natural range of tropical forest habitats. Indeed, Ae. luteocephalus can be found in forests, savannah, mangrove gallery forest and also in intermediate landscapes between sylvatic and urban areas $[15,17,20]$. Bionomically the specie utilizes varied range of breeding places as rot holes, tree holes, rock holes, bamboos, bamboo stems, tree fork, plastic bottles and artificial containers in height up to 9 metres [15-20]. Aedes luteocephalus breeding sites with similar features have also been reported elsewhere and in association with Ae. africanus, of the same group, but not to our knowledge, with Ae. vittatus, which is not surprising, as this later species also favors rock pools [15-20].

Preliminary analysis of the nucleotide sequences of cox $1 \mathrm{mtDNA}$ obtained from the 4 males revealed completely identical sequences, which suggests that the $A e$. luteocephalus larvae sequenced were siblings [28], possibly hatched from eggs laid by a single female, as mtDNA is maternally inherited, quite possible given the small dimensions of the breeding rock pool (Additional file 1: Figure S1).

Laboratory experiments have shown that Ae. luteocephalus can transmit yellow fever with an efficiency comparable to Ae. aegypti [23], readily bites humans and is involved in the transmission of YFV in West and Central Africa, and chikungunya virus (CHIKV), ZIKV and DENV2 have been isolated from it in West Africa [15]. Although Ae. luteocephalus habitat has been essentially rural and sylvatic, increasing demographical expansion and human pressure on forest resources, for logging and farming as it has been observed in the studied place. This condition might also increase the likelihood of vectorhuman and, therefore, the risk of rural arbovirus epidemics. Therefore, additional studies are urgently needed to investigate the effect of anthropogenic activity on arboviruses transmission risk in Lago District.

All Ae. luteocephalus specimens collected in this study, had a distinct middle longitudinal yellow stripe of thin scales in the scutum region; scutellum with wide white scales on lateral lobes; basal pale band on terga II-VI more yellow; and hind femur anteriorly with a huge light band at base and alongside two sizable white spots on median and apical regions (Fig. 1). These characteristics 


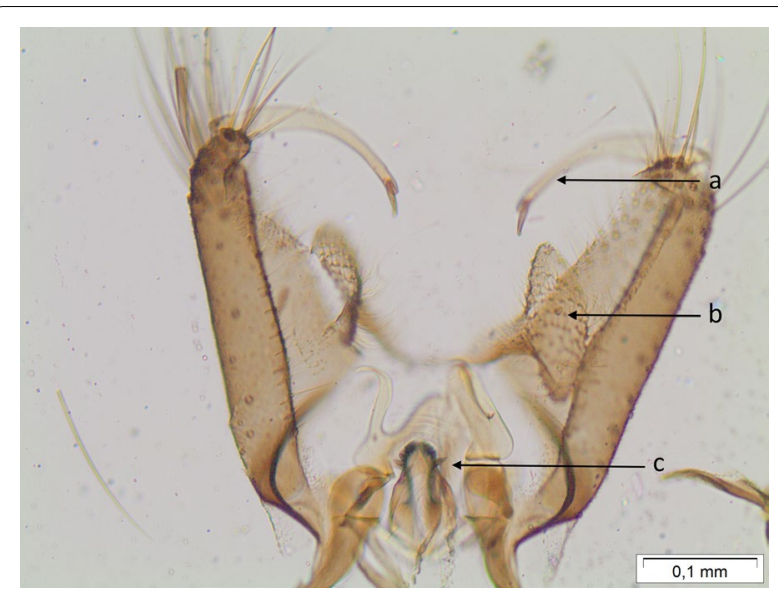

Fig. 2 Dissected male genitalia of Aedes luteocephalus showing gonocoxites with gonostylus (a) with gonostylar claw and claspette (b) large, lobed with distal expanded portion, oval in dorsal view, with numerous simple setae on the apicolateral portion, and with some short setae on the apicomesal portion and aedeagus (c) at $100 \times$ magnification. Scale-bar: $100 \mu \mathrm{m}$

are similar to those described by Huang [15] and Jupp [21].

All four dissected male genitalia showed gonocoxites with gonostylus simple with few setae in the apical quarter and a long slender gonostylar claw, claspette large, lobed, with distal expanded portion, oval in dorsal view, with numerous simple setae on the apicolateral portion, and with some short setae on the apicomesal portion (Fig. 2). These are considered the most important distinctive features that separate the species from other members of the africanus group, namely, Aedes (Stg.) africanus, to which it belongs $[15,21]$.
Barcode gene sequences of all specimens analyzed displayed 97.65-98.12\% sequence identity with homologues using BLAST (MegaBlast option) and 97.82-98.26\% identity in the BOLDSYSTEMS database with sequences of Ae. luteocephalus from Tanzania and Kenya, thereby confirming its taxonomic identity [19, 20, 22]. These findings represent, as far as we are aware, the first confirmed record of Ae. luteocephalus in Mozambique, while all other specimens collected in this survey correspond to taxa already known for the country. Additionally, phylogenetic reconstruction analysis carried out on the basis of a dataset of multiple Aedes species of the subgenera Stegomyia, Aedimorphus, Neomelaniconion and Ochlerotatus, clearly placed the cox 1 sequences obtained in the course of this study in a topologically stable monophyletic cluster that only included Ae. luteocephalus reference sequences (Fig. 3). This further confirms the morphological, barcode and sequence similarity-based identifications presented above. Therefore, our results clearly confirm that Ae. luteocephalus collected in the study area are quite similar to those from the neighboring countries Tanzania and Kenya [19, 20, 22] and have now been found as part of a wide survey in the country for vectors of arboviruses Abílio et al., unpublished data). Further haplotype network analyses are recommended to ensure for robust inference of exact origin of Ae. luteocephalus from Mozambique.

\section{Conclusions}

Comparative morphological, molecular and phylogenetic analyses have consistently shown, for the first time, the occurrence in Mozambican territory of Ae. luteocephalus, a competent vector of yellow fever virus and dengue fever virus in Africa. This finding may help fill the gaps of our knowledge about the distributional ecology of this important and overlooked arbovirus vector. Further field

(See figure on next page.)

Fig. 3 Maximum likelihood phylogenetic tree based on partial Aedes cox 1 sequences. Nodal support values $\geq 75$ are shown. The reference sequences used are indicated with either their GenBank accession number or BoldSystems code. The sequences generated in this study are indicated in bold by their laboratory code and accession numbers and are grouped in a monophyletic cluster indicated as Moz cluster. The scale-bar indicates the number of nucleotide substitutions per site 


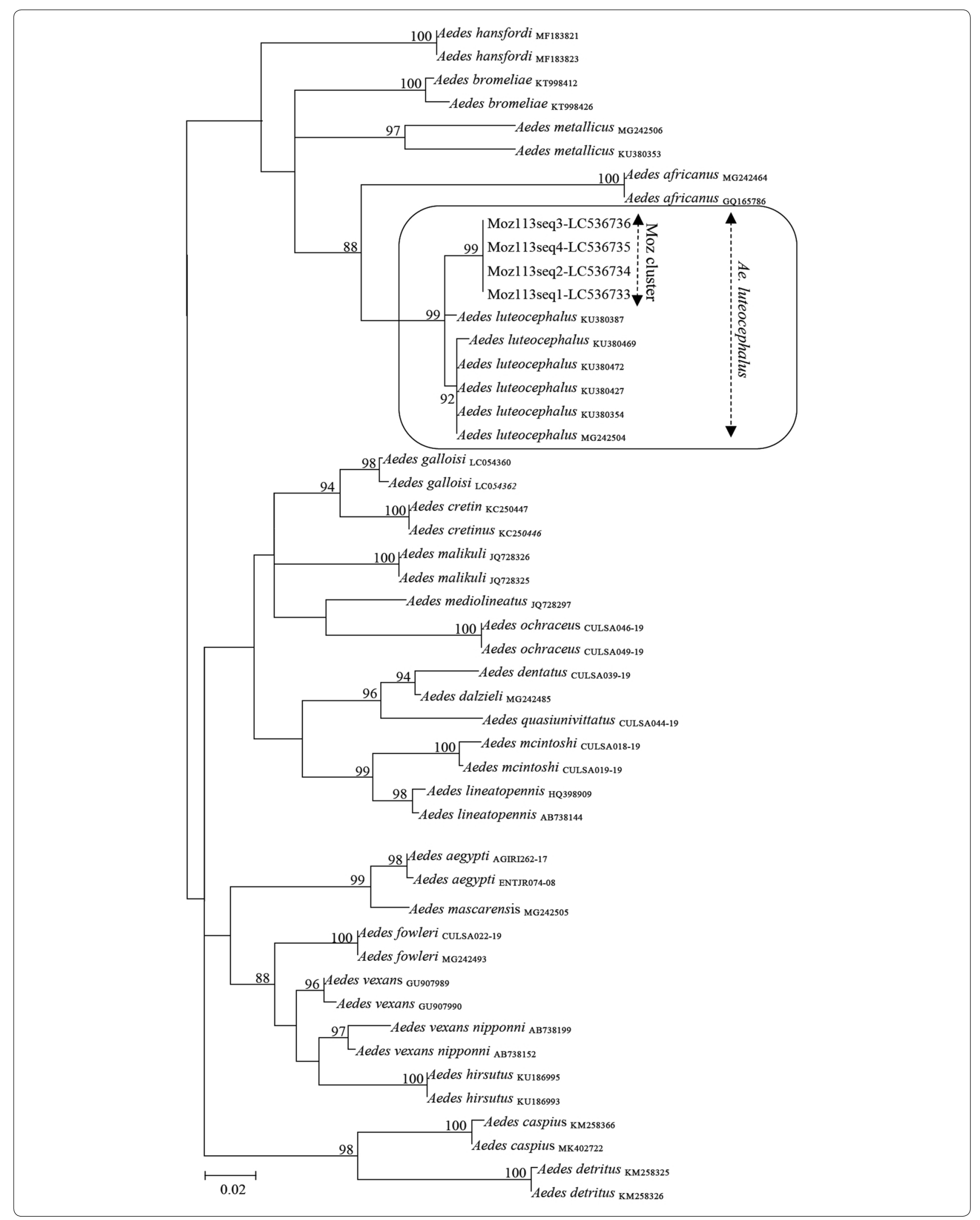


and laboratory surveys are encouraged to investigate the role of Ae. luteocephalus in the transmission of arboviruses in Mozambique.

\section{Supplementary information}

Supplementary information accompanies this paper at https://doi. org/10.1186/s13071-020-04217-9.

Additional file 1: Figure S1. Corresponding author collecting larvae of Ae. luteocephalus in a rock-pool with clear water approximately $20 \times$ $15 \mathrm{~cm}$, located at the Luaui riverbank, Lago District, neighbourhood of Maniamba, Niassa Province, northern Mozambique.

\section{Acknowledgements}

The authors thank people and authorities from Lago District for their cooperation during the fieldwork. This project was made possible also because of unconditional support of Direcçao Provincial de Saúde de Niassa (DPSN). Thanks are also due to Mr Muloiwa and Mr João, the technical personnel from the Insectary from Health Directorate of Niassa Province in Mozambique. We are grateful to the staff of the Entomology Unit, Institute of Hygiene and Tropical Medicine (IHMT), Lisbon, Portugal, for assistance with illustrations.

\section{Authors' contributions}

APA and APGA conceived the study. APA, EJA and AK performed field surveys and preliminary data analysis. APGA and RP performed molecular analysis and phylogenetic analysis. APA, AK, RP and APGA reanalysed the data and wrote the draft of the manuscript. APGA performed genitalia dissection and photographs. ESG, RP, LCBN, JMF, MS and APGA contributed with reagents, materials and equipment and reviewed the manuscript. All authors read and approved the final manuscript.

\section{Funding}

This study received main funding from Wellcome Trust (Grant WT087546MA) as part of APA, SACIDS RVF PhD fellowship. Additional funding was provided for travel in the country and abroad by NPHI-Phase-II from the National Institute of Health of Mozambique through a cooperative agreement number 5NU14GH001237-03-00. Global Health and Tropical Medicine Center has funded part of laboratory analyses through FCT contract UID/ Multi/04413/2013. The funding institutions had no role in study design, data collection, data analysis, manuscript writing and decision to publish.

\section{Availability of data and materials}

The datasets used and/or analyzed during the present study are available from the corresponding author upon reasonable request.

\section{Ethics approval and consent to participate}

The study was approved by the Mozambican National Bioethics Committee (Ref \#: 05/CNBS/ 2016) and the Faculty of Medicine of Eduardo Mondlane University (Ref \#: CIBS FM\&HCM/15/2018).

\section{Consent for publication}

Not applicable.

\section{Competing interests}

The authors declare that they have no competing interests.

\section{Author details}

${ }^{1}$ Instituto Nacional de Saúde (INS), Maputo, Província de Maputo, Mozambique. ${ }^{2}$ Centro de Biotecnologia, Universidade Eduardo Mondlane (UEM), Maputo, Mozambique. ${ }^{3}$ Direcção Provincial de Saúde de Niassa (DPSN), Lichinga, Mozambique. ${ }^{4}$ Department of Veterinary Tropical Diseases, University of Pretoria (UP), Pretoria, South Africa. ${ }^{5}$ GHTM, Institute of Hygiene and Tropical Medicine (IHMT), Universidade Nova de Lisboa, Lisboa, Portugal.
Received: 20 April 2020 Accepted: 6 July 2020

Published online: 06 October 2020

\section{References}

1. Knight KL, Stone A. A catalog of the mosquitoes of the world (Diptera: Culicidae). Washington DC: Entomological Society of America; 1977.

2. Campbell-Lendrum D, Manga L, Bagayoko M, Sommerfeld J. Climate change and vector-borne diseases: what are the implications for public health research and policy? Philos Trans R Soc Lond B Biol Sci. 2015;370:1665

3. Bhatt $\mathrm{S}$, Gething PW, Brady OJ, Messina JP, Farlow AW, Moyes $\mathrm{CL}$, et al. The global distribution and burden of dengue. Nature. 2013;496:504-7.

4. WHO. Yellow fever in Africa and South America, 2011-2012. Geneva: World Health Organization; 2013. https://www.who.int/news-room/factsheets/detail/yellow-fever.

5. WHO. A global brief on vector-borne diseases. Geneva: World Health Organization; 2014. https://apps.who.int/iris/handle/10665/111008.

6. Abílio AP, Abudasse G, Kampango A, Candrinho B, Sitoi S, Luciano J, et al. Distribution and breeding sites of Aedes aegypti and Aedes albopictus in 32 urban/peri-urban districts of Mozambique: implication for assessing the risk of arbovirus outbreaks. PLoS Negl Trop Dis. 2018;12:e0006692.

7. Waggoner JJ, Gresh L, Vargas MJ, Ballesteros G, Tellez Y, Soda KJ, et al. Viremia and clinical presentation in Nicaraguan patients infected with Zika virus, chikungunya virus, and dengue virus. Clin Infect Dis. 2016;63:1584-90.

8. Chippaux JP, Chippaux A. Yellow fever in Africa and the Americas: a historical and epidemiological perspective. J Venom Anim Toxins Incl Trop Dis. 2018;24:20

9. Kampango A, Abílio AP. The Asian tiger hunts in Maputo city - the first confirmed report of Aedes (Stegomyia) albopictus (Skuse, 1895) in Mozambique. Parasit Vectors. 2016;9:76.

10. Worth CB, De Meillon B. Culicine mosquitoes (Diptera:Culicidae) recorded from the Province of Mozambique (Portuguese East Africa) and their relation to arthropod-borne virus. An Inst Med Trop (Lisb). 1960;17:231-56.

11. Cholleti H, Hayer J, Abilio AP, Mulandane FC, Verner-Carlsson J, Falk KI, et al. Discovery of novel viruses in mosquitoes from the Zambezi valley of Mozambique. PloS One. 2016;11:e0162751.

12. Arroz JA. Increase in cases of malaria in Mozambique, 2014: epidemic or new endemic pattern? Rev Saude Publica. 2016;50:5.

13. Massangaie M, Pinto G, Padama F, Chambe G, da Silva M, Mate I, et al. Clinical and epidemiological characterization of the first recognized outbreak of dengue virus-type 2 in Mozambique, 2014. Am J Trop Med Hyg. 2016;94:413-6.

14. Higa Y, Abilio AP, Futami K, Lazaro MA, Minakawa N, Gudo ES. Abundant Aedes (Stegomyia) aegypti aegypti mosquitoes in the 2014 dengue outbreak area of Mozambique. Trop Med Health. 2015;43:107-9.

15. Huang Y-M. The subgenus Stegomyia of Aedes in Afrotropical region I. The africanus group of species (Diptera: Culicidae). Contrib Am Entomol Inst. 1990;26:3-90.

16. Huang Y-M. The subgenus Stegomyia of Aedes in the Afrotropical region with keys to the species (Diptera: Culicidae). Zootaxa. 2004;700:1.

17. Diagne CT, Diallo D, Faye O, Ba Y, Faye O, Gaye A, et al. Potential of selected Senegalese Aedes spp. mosquitoes (Diptera: Culicidae) to transmit Zika virus. BMC Infect Dis. 2015;15:492.

18. Newstead R, Everett Dutton J, Todd JL, McGill CM. Insect and other Arthropoda collected in the Congo free State. Ann Trop Med Parasitol. 1907;1:3-113.

19. Germain M, Cornet M, Mouchet J, Herve JP, Robert V, Camicas JL, et al. [Sylvatic yellow fever in Africa recent advances and present approach, La fievre jaune selvatique en Afrique: donnees recentes et conceptions actuelles. (author's transl)]. Med Trop (Mars). 1981;41:31-43.

20. Mutebi JP, Crabtree MB, Kading RC, Powers AM, Lutwama JJ, Miller BR. Mosquitoes of western Uganda. J Med Entomol. 2012;49:1289-306.

21. Jupp PG. Mosquitoes of southern Africa: Culicinae and Toxorhynchitinae. Johannesburg: South Africa: Ekogilde Publishers; 1996.

22. Muspratt J. The Stegomyia mosquitoes of South Africa and some neighbouring territories. Including chapter on the mosquitoes-born virus diseases of the Ethiopian zoogeographical region of Africa. Men Ent Soc Sth Afr. 1956:4:1-138. 
23. Bauer HJ. The transmission of yellow fever by mosquitoes other than Aedes aegypti. Am J Trop Med Hyg. 1928;1-8:261-82.

24. Gaye A, Wang E, Vasilakis N, Guzman H, Diallo D, Talla C, et al. Potential for sylvatic and urban Aedes mosquitoes from Senegal to transmit the new emerging dengue serotypes 1, 3 and 4 in West Africa. PLoS Negl Trop Dis. 2019;13:e0007043.

25. WHO. Operational guide for assessing the productivity of Aedes aegypti breeding sites. Geneva: World Health Organization; 2011.

26. WHO. Manual on practical entomology in malaria. Part II: methods and techniques. Geneva: World Health Organization; 1975.

27. Ribeiro $\mathrm{H}$. A solidifiable formic acid-PVA solution for transporting, preserving and mounting mosquito larvae and pupae. Stain Technol. 1967:42:158-60.

28. Mixao V, Bravo Barriga D, Parreira R, Novo MT, Sousa CA, Frontera E, et al. Comparative morphological and molecular analysis confirms the presence of the West Nile virus mosquito vector, Culex univittatus, in the Iberian Peninsula. Parasit Vectors. 2016;9:601.

29. Gillies MT, De Meillon B. The Anophelinae of the Africa south of the Sahara (Ethiopian zoographical region). Publ South African Inst Med Res. 1968:54:1-343.
30. Folmer O, Black M, Hoeh W, Lutz R, Vrijenhoek R. DNA primers for amplification of mitochondrial cytochrome c oxidase subunit I from diverse metazoan invertebrates. Mol Mar Biol Biotechnol. 1994;3:294-9.

31. Clark K, Karsch-Mizrachi I, Lipman DJ, Ostell J, Sayers EW. GenBank. Nucleic Acids Res. 2016:44:D67-72.

32. Ratnasingham S, Hebert PD. Bold: The Barcode of Life Data System (http://www.barcodinglife.org). Mol Ecol Notes. 2007:7:355-64.

33. Katoh K, Standley DM. MAFFT multiple sequence alignment software version 7: improvements in performance and usability. Mol Biol Evol. 2013;30:772-80.

34. Castresana J. Selection of conserved blocks from multiple alignments for their use in phylogenetic analysis. Mol Biol Evol. 2000;17:540-52.

35. Hall TA. BioEdit: a user-friendlybiological sequence alignment editor and analysis program for Windows 95/98/NT. Nucleic Acids Symp Ser. 1999:4:95-8.

36. Darriba D, Taboada GL, Doallo R, Posada D. jModelTest 2: more models, new heuristics and parallel computing. Nat Methods. 2012;9:772.

37. Trifinopoulos J, Nguyen LT, von Haeseler A, Minh BQ. W-IQ-TREE: a fast online phylogenetic tool for maximum likelihood analysis. Nucleic Acids Res. 2016;44:W232-5.

\section{Publisher's Note}

Springer Nature remains neutral with regard to jurisdictional claims in published maps and institutional affiliations.
Ready to submit your research? Choose BMC and benefit from:

- fast, convenient online submission

- thorough peer review by experienced researchers in your field

- rapid publication on acceptance

- support for research data, including large and complex data types

- gold Open Access which fosters wider collaboration and increased citations

- maximum visibility for your research: over $100 \mathrm{M}$ website views per year

At BMC, research is always in progress.

Learn more biomedcentral.com/submissions 